\title{
Respiratory Syncytial Virus Immunoprophylaxis with Palivizumab: 12-Year Observational Study of Usage and Outcomes in Canada
}

\author{
Ian Mitchell, FRCPC ${ }^{1}$ Abby Li, MSc ${ }^{2}$ Candice L. Bjornson, FRCPC ${ }^{1}$ Krista L. Lanctot, $\mathrm{PhD}^{2}$ \\ Bosco A. Paes, FRCPC ${ }^{3}$ and the CARESS investigators
}

${ }^{1}$ Department of Paediatrics, University of Calgary, Alberta Children's Hospital, Calgary, Alberta, Canada

2 Medical Outcomes and Research in Economics, Sunnybrook Health Sciences, Centre, Toronto, Ontario, Canada

${ }^{3}$ Department of Pediatrics, McMaster University, Hamilton, Ontario, Canada Am J Perinatol 2022;39:1668-1677.
Address for correspondence lan Mitchell, FRCPC, Department of Paediatrics, University of Calgary, Alberta Children's Hospital, 28 Oki Drive NW, Calgary, Alberta T3B 6A8, Canada (e-mail: imitche@ucalgary.ca).

\section{Abstract \\ Keywords \\ - RSV infection \\ - palivizumab \\ - prematurity \\ - bronchopulmonary dysplasia \\ - chronic lung disease \\ - hemodynamically significant congenital heart disease \\ - children with medical complexity}

Objective This study aimed to evaluate palivizumab (PVZ) use, trends in indications, and outcomes of respiratory illness hospitalizations $(\mathrm{RIH})$ and respiratory syncytial virus hospitalizations (RSVH).

Study Design It involves a large, Canadian prospective (2005-2017) observational multicenter study of children at high risk for RSV infection.

Results A total of 25,003 infants (56.3\% male) were enrolled at 32 sites; 109,579 PVZ injections were administered. Indications included: prematurity (63.3\%); "miscellaneous" (17.8\%); hemodynamically significant congenital heart disease (10.5\%); bronchopulmonary dysplasia/chronic lung disease (8.4\%). The "miscellaneous" group increased over time (4.4\% in 2005-2006 to $22.5 \%$ in 2016-2017) and included: trisomy 21, airway anomalies, pulmonary disorders, cystic fibrosis, neurological impairments, immunocompromised, cardiac aged $>2$ years, multiple conditions, and a residual "unclassified" group. Adherence measured by expected versus actual doses plus correct interdose interval was 64.7\%. A total of 2,054 RIH occurred (6.9\%); 198 (9.6\%) required intubation. Three hundred thirty-seven hospitalized children were RSV-positive (overall RSVH 1.6\%). Risk factors for RSVH included having siblings, attending daycare, family history of atopy, smoking exposure, and crowded household. Infants with 5 risk factors were 9.0 times $(95 \% \mathrm{Cl}$ or confidence interval 4.4-18.2; $p<0.0005)$ more likely to have RSVH than infants without risk factors. Three adverse events occurred; none were fatal.

Conclusion Results are relevant to both clinicians and decision-makers. We confirmed the safety of PVZ. Use of PVZ increased steadily for children with miscellaneous conditions and medical complexity. Medical and social factors pose a risk for severe RIH and RSVH with accompanying burden of illness. A vaccine that protects against RSV is urgently required. received

July 10,2020 accepted after revision January 19, 2021 published online March 3, 2021
DOI https://doi.org/ 10.1055/s-0041-1725146 ISSN 0735-1631.

\footnotetext{
(C) 2021. The Author(s).

This is an open access article published by Thieme under the terms of the Creative Commons Attribution-NonDerivative-NonCommercial-License, permitting copying and reproduction so long as the original work is given appropriate credit. Contents may not be used for commercial purposes, or adapted, remixed, transformed or built upon. (https://creativecommons.org/ licenses/by-nc-nd/4.0/) Thieme Medical Publishers, Inc., 333 Seventh Avenue, 18th Floor, New York, NY 10001, USA
} 


\section{Key Points}

- Main indications were prematurity (63.3\%); "miscellaneous" (17.8\%); hemodynamically significant congenital heart disease (10.5\%); bronchopulmonary dysplasia/chronic lung disease (8.4\%).

- The proportion of children in the "miscellaneous" group, comprised of those with trisomy 21, airway anomalies, pulmonary disorders, cystic fibrosis, neurological impairments, immunocompromised, cardiac aged $>2$ years, multiple conditions, and a residual "unclassified" group, increased over time (4.4\% in 2005-2006 to 22.5\% in 2016-2017).

- Respiratory illness-related hospitalization occurred in 2,054 children (6.9\%); 198 (9.6\%) required intubation. Three hundred thirty-seven hospitalized children were RSV-positive (overall RSVH: 1.6\%).

Respiratory syncytial virus (RSV) is the commonest pathogen in severe lower respiratory tract disease in infancy and childhood. ${ }^{1}$ The risk of severe RSV infection is increased in the very young infants, and in those with co-morbidities such as prematurity, bronchopulmonary dysplasia/chronic lung disease (BPD/CLD), hemodynamically significant congenital heart disease (HSCHD), and congenital anomalies. There is currently no RSV vaccine, but promising candidates are in development. ${ }^{2}$ Palivizumab (PVZ), a monoclonal antibody, is safe and efficacious against RSV during the epidemic season. ${ }^{3}$ Randomized placebo-controlled double-blind trials (RCTs) have confirmed the benefit of PVZ for primary indications that include preterm infants, those with BPD/CLD $(n=1,502),{ }^{4}$ and infants with HSCHD $(n=1,287) .^{5}$

The Canadian Registry of PVZ (CARESS) documents health outcomes in infants receiving prophylaxis. Decisions to use PVZ are taken by the children's physicians in association with Canadian provincial programs. The provincial programs adopt the Canadian Pediatric Society guidelines ${ }^{6}$ for PVZ use as a basis for their recommendations but include additional categories. Of note, five doses of PVZ are approved and funded by each provincial government for primary indications that include: preterm infants; BPD/CLD; and infants with HSCHD. Similarly. funding is granted for infants with complex medical disorders on a case-by-case basis once approved by the respective RSV advisory board that collaborates with the relevant provincial government agency. We previously reported on 5,286 infants in the study from 2005 to 2009 who received prophylaxis for prematurity (70.8\%), BPD/CLD (8.5\%), HSCHD (9.6\%), and miscellaneous complex medical conditions (11.1\%). ${ }^{7}$ The RSV hospitalization (RSVH) and respiratory illness hospitalization $(\mathrm{RIH})$ rate was 1.38 , and $5.8 \%$ respectively. Data from four other countries show that RIH and RSVH rates closely align with the CARESS study. ${ }^{8}$

PVZ is recommended in infants with disorders other than prematurity, BPD/CLD, and HSCD, ${ }^{9,10}$ but evidence supporting such use is from smaller clinical studies as compared with the RCTs in infants preterm or with HSCHD. ${ }^{4,5}$ Several countries have reported on the use of PVZ for miscellaneous conditions in addition to the primary indications with some focused on specific diagnostic groups. ${ }^{11-18}$ Few studies have reported on overall PVZ use for both primary and a large group of miscellaneous conditions. ${ }^{19,20}$

Over the period of this study, clinical practice has seen changes that may have impacted PVZ use and concomitant outcomes, including neonatal care, ${ }^{21}$ newborn screening for cystic fibrosis, ${ }^{22}$ and a marked increase in the survival of children with complex medical conditions. ${ }^{23}$ We report on 25,003 children in the CARESS study from 2005 through 2017 RSV seasons. The study objectives are to describe PVZ use, trends in indications including diagnoses impacted by medical practice changes, and outcomes including RIH and RSVH, from a large prospective observational multicenter study of children at high risk for RSV.

\section{Materials and Methods}

These have been described previously. ${ }^{7}$ In summary, approval was obtained from the Institutional Ethics Review Boards of all participating centers, and the work was performed in accordance with the Code of Ethics of the World Medical Association (Declaration of Helsinki). Inclusion criterion was any child receiving at least one dose of PVZ whatever the indication. The exclusion criterion was any child who had received PVZ as part of a clinical trial during the study period. Staff at the individual sites enrolled children whose legal guardian spoke English or French. Individual programs determine when the first dose is given based on the start of the local RSV season. The factors that are considered when determining when to start and when to end a program are described by Law et al. ${ }^{24}$ The effects of different methods used to determine start and end dates have been described for the Province of Ontario. ${ }^{25}$ Given the cost implications, start and end dates are always considered carefully, and this factor in addition to different historic trends on start and end dates for RSV epidemics, explains the variation across Canada.

Baseline data were collected after enrollment followed by monthly interviews until the end of the RSV season. Baseline data included neonatal history and course and information on multiple births, gender, ethnicity, and family history of atopy. Questions were asked at enrollment and then monthly on tobacco exposure, daycare attendance (subject or siblings), household composition, and possible adverse events. After a respiratory illness, the details of presentation and course were obtained from the child's medical chart. These methods were consistent over the course of the study.

\section{Definitions and Outcomes}

Adherence to treatment was defined as follows: (1) expected number of doses versus actual number of doses for the respective RSV season, and (2) interdose interval. For the first definition, the number was calculated assuming monthly injections from the first dose to the end of the RSV season. For the second definition, $30 \pm 5$ day intervals were considered 
as adherent. Some centers used an interval of $20 \pm 4$ days between the first and second injections, to possibly yield higher trough levels after the first dose and avoid breakthrough RSV infection. Therefore, an interval of 16 to 35 days between the first and second injection was considered adherent. Hospitalizations were defined by two primary end points: RIH and RSVH. We compared hospitalized versus nonhospitalized patients to identify potential risk factors for hospitalization.

The RIH rate was determined by the number of children hospitalized for respiratory-related illnesses divided by the total number of children in the study population. The RSVH rate was calculated by multiplying the RIH by the number of RSV-positive children divided by the number of children tested for RSV infection.

\section{Statistical Analysis}

All data were examined using SPSS v. 17.0. ${ }^{26}$ The statistical tests employed were Student $t$-test, analysis of variance (ANOVA) for continuous variables, and Pearson Chi-square test for nominal variables. A $p$-value of 0.05 was considered as the limit of significance. To examine any factors that may affect time to hospitalization, a Cox proportional analysis was conducted using a backward conditional method. The time variable used was the number of days between a patient's first PVZ injection and their first $\mathrm{RSVH}$; for those who were not hospitalized for RSV, the number of days between their first injection and their last day of observation was used. Covariates were chosen a priori and accounted for based on variables that were shown to be correlated to time to hospitalization for either RIH or RSVH.

A subanalysis of the demographics, indications for prophylaxis, and outcomes (RIH and RSVH) was conducted on infants less than and greater than 2 years.

\section{Results}

A total of 25,003 children were enrolled during the 12 RSV seasons of the CARESS study between October 1, 2005 and
May 31, 2017. Enrollment occurred in 32 sites across Canada, with regional enrolment in CARESS similar to proportions in Canadian population statistics ( - Fig. 1 ). The infants enrolled were predominantly male (56.3\%) and Caucasian (68.6\%). On average, infants were $5.7 \pm 6.4$ months of age when enrolled and had completed $32.6 \pm 5.0$ weeks of gestation. Events during the neonatal course are shown in -Table 1. Respiratory support of the subjects, including supplementary oxygen therapy during the neonatal intensive care unit course, was required in more than half (59.9\%). All aspects of neonatal care were statistically different between the primary indications and was most marked in the BPD/CLD group.

A total of 15,821 children (63.3\%) received prophylaxis for prematurity, 2,626 (10.5\%) for HSCHD, 2,104 (8.4\%) for BPD/CLD, and 4,452 (17.8\%) for "miscellaneous" indications. The majority of infants who received prophylaxis in the "miscellaneous" category could be grouped into seven diagnostic groups, an eighth group with more than one condition, and a final group that remained unclassified ( - Table 2 ). The "unclassified" group comprised numerous conditions inclusive of gastroschisis with severe failure to thrive, lysosomal and other metabolic disorders, and hepatic failure awaiting transplant. The variation over time is shown in - Fig. 2. The percentage of subjects who received PVZ in the "miscellaneous" group rose from 4.4\% (2005-2006) to $22.5 \%$ in the 2016 to 2017 RSV season. Most of the children $(n=24,527)$, were aged $<2$ years with 426 who were $>2$ years of age. The demographics of those $<2$ years of age versus those aged $>2$ years are shown in - Table 3 , and a comparison of the major indications for prophylaxis of those aged $<2$ years and $>2$ years is shown in - Table 4 .

A total of 109,579 injections were administered to the 25,003 children enrolled in the study. 14,986 (59.9\%) received five or more injections. Each child received an average of $4 \pm 1$ injections per season, and a median and mode of 5 injections per child.

Based on definition 1 of adherence, 20,964 (83.8\%) children received at least all of their expected injections across all 12 seasons of CARESS. Based on definition 2 of adherence (interinjection interval), 18,485 (73.9\%) of children were adherent.

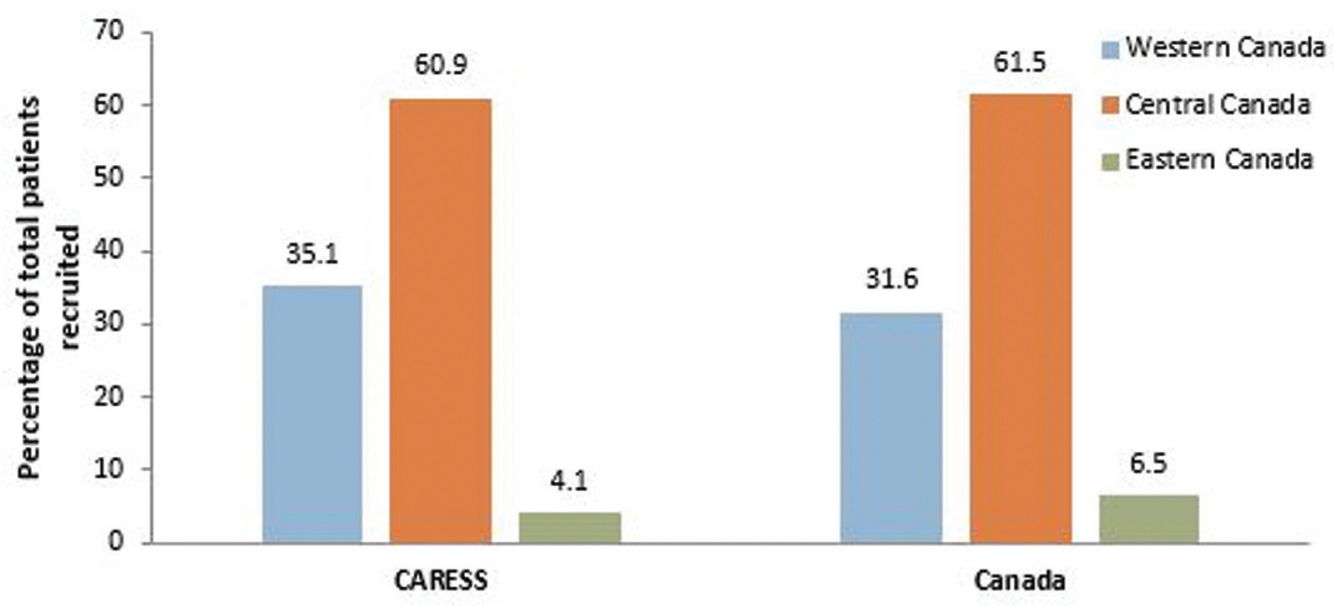

Fig. 1 Comparison of the geographical distribution among the CARESS and Canadian populations. CARESS, Canadian Respiratory Syncytial Virus Evaluation Study of Palivizumab. 
Table 1 Neonatal hospitalization events by indication

\begin{tabular}{|llllll|}
\hline & Total & Premature & BPD/CLD & HSCHD & Miscellaneous \\
& $N=25003$ & $N=15,821$ & $N=2,103$ & $N=2,628$ & $n=4,452$ \\
Days of neonatal stay (mean \pm SD) & $48.8 \pm 67.3$ & $45.3 \pm 57.1$ & $99.4 \pm 86.8$ & $34.4 \pm 62.4$ & $44.6 \pm 79.1$ \\
Respiratory support (\%) & $14,982(59.9)$ & $10,507(66.4)$ & $1,658(78.8)$ & $1,038(39.5)$ & $1,779(40.0)$ \\
Duration in days (mean \pm SD) & $24.0 \pm 38.4$ & $18.1 \pm 24.1$ & $58.1 \pm 54.0$ & $17.1 \pm 26.2$ & $31.5 \pm 67.2$ \\
Oxygen therapy (\%) & $12,235(48.9)$ & $7,482(47.3)$ & $1,786(84.9)$ & $1,108(42.2)$ & $1,859(41.8)$ \\
Duration in days (mean \pm SD) & $34.5 \pm 61.8$ & $22.2 \pm 34.6$ & $95.2 \pm 103.0$ & $25.3 \pm 52.2$ & $33.2 \pm 68.6$ \\
Documented necrotizing enterocolitis (\%) & $723(2.9)$ & $434(2.7)$ & $140(6.7)$ & $60(2.3)$ & $89(2.0)$ \\
Documented sepsis (\%) & $3,304(13.3)$ & $1,910(12.1)$ & $680(32.6)$ & $222(8.5)$ & $492(11.1)$ \\
Surgery for patent ductus arteriosus (\%) & $1,157(4.6)$ & $472(3.0)$ & $367(17.5)$ & $199(7.6)$ & $119(2.7)$ \\
\hline
\end{tabular}

Abbreviations: BPD, bronchopulmonary dysplasia; CLD, chronic lung disease; HSCHD, hemodynamically significant congenital heart disease; PICU, pediatric intensive care unit; SD, standard deviation.

\begin{tabular}{|lll|}
\hline $\begin{array}{l}\text { Table 2 Diagnostic } \\
\text { classification }\end{array}$ & groups in the “miscellaneous" \\
\hline Diagnostic group & $n$ & $\%$ \\
Trisomy 21 & 942 & 21.2 \\
Airway anomaly & 855 & 19.2 \\
Neurological & 471 & 10.6 \\
Cystic fibrosis & 442 & 9.9 \\
Pulmonary & 438 & 9.8 \\
Multiple conditions & 190 & 4.3 \\
Immunocompromised & 162 & 3.6 \\
Cardiac $>2$ y of age & 99 & 2.2 \\
Unclassified & 853 & 19.2 \\
Total & 3,929 & 100.00 \\
\hline
\end{tabular}

"Perfect" adherence, that is those children meeting both criteria for definitions 1 and 2, was met by 16,168(64.7\%) of the infants.

Of the 25,003 infants enrolled, 1,724 infants were hospitalized 2,054 times, giving an RIH rate of $6.9 \%$. There is a trend of increasing hospitalization rates, with a low of $3.3 \%$ hospitalized in the 2005 to 2006 season and a high of $8.3 \%$ in the 2014 to 2015 season, with a fall again in the most recent season (2016-2017) to a rate of 4.9\%. The main reasons for admission are shown in -Table 5 with respiratory distress being the leading cause for hospitalization (70.5\%), followed by bronchiolitis (50.3\%). - Table 5 also shows RIH in-hospital events. Of the 2,054 admissions, $450(21.9 \%)$ involved a stay in the pediatric intensive care unit (PICU), 623 (30.3\%) required respiratory support, and 198 (9.6\%) required intubation.

Of the 1,724 subjects that were hospitalized, RSV tests were conducted on 1,474; 334 tested RSV-positive a total of 339 times, giving an RSV-positive rate of $19.5 \%$. The overall

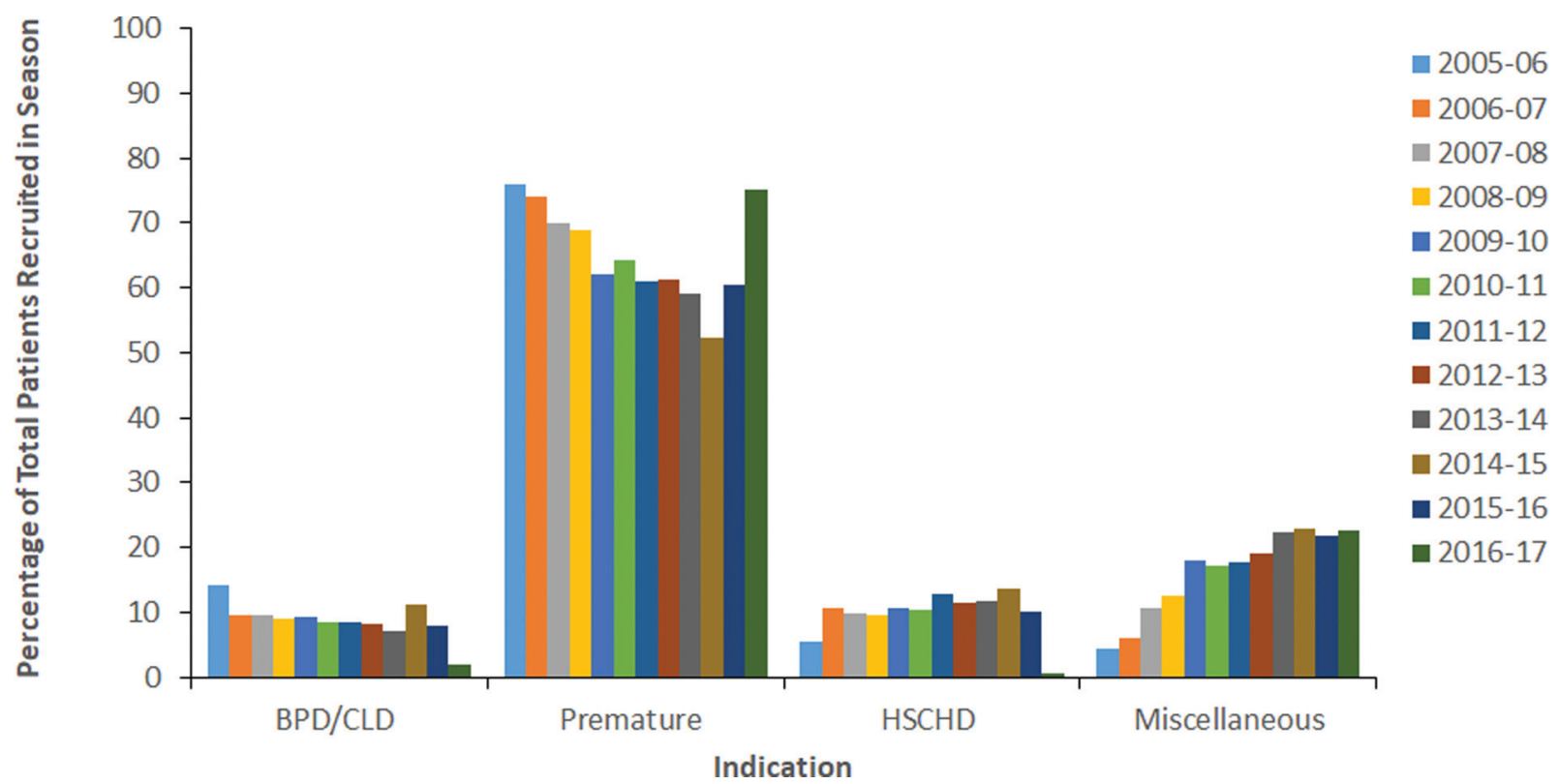

Fig. 2 Changing proportions of indications for palivizumab by RSV season. BPD, bronchopulmonary dysplasia; CLD, chronic lung disease; HSCHD, hemodynamically significant congenital heart disease; RSV, respiratory syncytial virus. 
Table 3 Demographics of children less than 2 years of age versus those aged greater than 2 years

\begin{tabular}{|c|c|c|c|c|}
\hline & $\begin{array}{l}\text { Age }<2 \text { y } \\
n=24,527\end{array}$ & $\begin{array}{l}\text { Age } \geq 2 y \\
n=476\end{array}$ & $x^{2}$ or $t(\mathrm{~d} f)$ & p-Value \\
\hline Male (\%) & 13,831 & 252 & $2.345(1)$ & 0.135 \\
\hline Caucasian (\%) & 16,797 & 366 & $15.333(1)$ & $<0.0005$ \\
\hline Daycare attendance (\%) & 846 & 121 & $605.083(1)$ & $<0.0005$ \\
\hline Atopy in family (\%) & 9,802 & 232 & $18.610(1)$ & $<0.0005$ \\
\hline Multiple birth (\%) & 6,881 & 68 & $44.112(1)$ & $<0.0005$ \\
\hline Smoking in home (\%) & 6,492 & 107 & $3.826(1)$ & 0.053 \\
\hline With siblings (\%) & 15,646 & 333 & $7.699(1)$ & 0.005 \\
\hline With siblings in daycare (\%) & 4,592 & 111 & $6.462(1)$ & 0.012 \\
\hline With $\geq 5$ people in household (\%) & 5,944 & 101 & $2.317(1)$ & 0.132 \\
\hline Mean enrollment age (month \pm SD) & $5.1 \pm 5.0$ & $32.3 \pm 11.3$ & $-52.571(478.690)$ & $<0.0005$ \\
\hline Mean gestational age $(w k \pm S D)$ & $32.5 \pm 4.4$ & $36.1 \pm 17.8$ & $-4.317(470.101)$ & $<0.0005$ \\
\hline Mean birth weight $(g \pm S D)$ & $1,925 \pm 959$ & $2,495 \pm 1,831$ & $-6.740(474.985)$ & $<0.0005$ \\
\hline Mean enrollment weight $(\mathrm{g} \pm \mathrm{SD})$ & $5,004 \pm 2,840$ & $10,915 \pm 3,362$ & $-37.978(485.356)$ & $<0.0005$ \\
\hline
\end{tabular}

Abbreviation: SD, standard deviation.

Table 4 Comparison of the major indications for palivizumab among children aged less than 2 years and greater than 2 years

\begin{tabular}{lll|}
\hline & Age $<\mathbf{2} \mathbf{y}, \boldsymbol{n}$ & Age $\geq \mathbf{2}$ y, $\boldsymbol{n}$ \\
BPD/CLD & 2,041 & 63 \\
Premature & 15,790 & 31 \\
HSCHD & 2,523 & 103 \\
Miscellaneous $^{\mathrm{a}}$ & 4,173 & 279 \\
\hline
\end{tabular}

Abbreviations: BPD, bronchopulmonary dysplasia; CLD, chronic lung disease; HSCHD, hemodynamically significant congenital heart disease. Note: $x^{2}=771.591, \mathrm{~d} f=3, p<0.0005$.

ancludes all children with complex medical disorders plus the unclassified group.

RSVH rate was $1.6 \%$. The number of infants hospitalized with RSV and the RSVH hospitalization rates by indication are shown in - Table 6. - Table 7 shows demographic differences between RSV-positive hospitalized children and RSV-negative children (hospitalized and not-hospitalized). Most risk factors associated with RSV infection were seen in greater proportions in the hospitalized than the nonhospitalized group ( $p<0.0005$ unless indicated otherwise).

Cox proportional regression (-Fig. 3) shows affected time to RSVH. The overall model was highly significant $\left(x^{2}\right.$ $[6]=94.7, p<0.0005)$. Factors that were found to be significant predictors of time to first RSVH are shown in - Table 8. Additive effects of risk factors on the time to RSVH were also observed. Infants with five risk factors were nine (95\% CI 4.4-18.2, $p<0.0005$ ) times more likely to be hospitalized with RSV than infants with no risk factors. The Cox proportional regression analysis of time to first RSVH based on indication showed significant differences between groups (Chi-square: $105.65, \mathrm{~d} f=8, p<0.0005$; - Fig. 4).

A total of three serious adverse events were reported for three infants. The indications for PVZ were: prematurity $(n=1)$, congenital airway anomaly $(n=1)$, and Trisomy 21 $(n=1)$. One of the three patients was hospitalized for a fine red rash after receiving the first injection of PVZ. None of the SAEs resulted in death; however, the causality of the SAEs was classified as having probable or possible relationship to PVZ treatment.

\section{Discussion}

These results on PVZ usage and outcomes in 25,003 children are from prospectively collected Canadian data (2005-2017), the largest database worldwide of children who received PVZ. Since the publication of an international comparison of PVZ use up to $2012,{ }^{8}$ there have been few further publications with a database comparable to CARESS. Heljic et al reported on 589 infants given PVZ for a range of indications in Bosnia and Herzegovina in the RSV seasons in 2008 to $2014 .{ }^{15}$ In the German $^{16} \quad(n=12,729 ; \quad 2009-2016), \quad \operatorname{Russian}^{27}(n=3200$; 2010-2014), and Polish ${ }^{28}(n=3780 ; 2008-2014)$ registries, PVZ was administered for primary indications in the majority.

Our overall RSVH rate of $1.6 \%$ is broadly similar to other studies $^{8}$ except the French report ${ }^{29}$ with an RSVH of $8.1 \%$. This may be explained by a higher proportion of infants with $\mathrm{BPD} / \mathrm{CLD}$. The more recent report from Germany had a lower RSVH of $0.7 \%$, but this study included very few children who did not have primary indications. The overall RSVH rate following PVZ in our study was lowest in the preterm population $(1.1 \%)$ and ranged from 0.8 to $3.2 \%$ across infants with $\mathrm{BPD} / \mathrm{CLD}, \mathrm{HSCD}$, and the miscellaneous category. Among the latter group the highest rates were noted in those prophylaxed for neurological disorders (3.2\%), cardiac disorders beyond 2 years of age (3.0\%), and children who were immunocompromised (2.5\%). The high RSVH rates in children $>24$ months of age align with recently published data and challenge the concept of an arbitrary cut-off for children with medical complexity. ${ }^{30}$ In this study, established risk factors for RSVH 


\begin{tabular}{|c|c|c|c|c|c|}
\hline & $\begin{array}{l}\text { Total } \\
N=2,054 \text { (\%) }\end{array}$ & $\begin{array}{l}\text { Premature } \\
N=754 \text { (\%) }\end{array}$ & $\begin{array}{l}\mathrm{BPD} / \mathrm{CLD} \\
N=350 \text { (\%) }\end{array}$ & $\begin{array}{l}\text { HSCHD } \\
N=366(\%)\end{array}$ & $\begin{array}{l}\text { Miscellaneous } \\
N=584(\%)\end{array}$ \\
\hline \multicolumn{6}{|l|}{ Reason for admission ${ }^{a}$} \\
\hline Apnea & $191(9.3)$ & $131(17.4)$ & $11(3.1)$ & $15(4.1)$ & $34(5.8)$ \\
\hline Bronchiolitis & $1,033(50.3)$ & $450(59.7)$ & $176(50.3)$ & $156(42.6)$ & $251(43.0)$ \\
\hline Decreased oxygen saturation ( $<93 \%)$ & $880(42.8)$ & $252(33.4)$ & $179(51.1)$ & 190 (51.9) & $259(44.4)$ \\
\hline Inability to maintain oral intake & $803(39.1)$ & $289(38.3)$ & $137(39.1)$ & $151(41.3)$ & $226(38.7)$ \\
\hline Pneumonia & $599(29.2)$ & $147(19.5)$ & $146(41.7)$ & $101(27.6)$ & $205(35.1)$ \\
\hline Respiratory arrest & $44(2.1)$ & $19(2.5)$ & $5(1.4)$ & $9(2.5)$ & 11 (1.9) \\
\hline Respiratory distress & $1,449(70.5)$ & $482(63.9)$ & 269 (76.9) & $262(71.6)$ & $436(74.7)$ \\
\hline Other & $936(45.6)$ & $304(40.3)$ & $174(49.7)$ & $169(46.2)$ & 289 (49.5) \\
\hline \multicolumn{6}{|l|}{ In-hospital event } \\
\hline Length of stay in days (mean $\pm S D$ ) & $8.2 \pm 16.2$ & $6.9 \pm 12.0$ & $8.1 \pm 18.0$ & $9.8 \pm 22.2$ & $9.0 \pm 15.2$ \\
\hline PICU admission (\%) & 450 (21.9) & $174(23.1)$ & $57(16.3)$ & $94(25.7)$ & $125(21.4)$ \\
\hline PICU length of stay in days (mean $\pm S D$ ) & $2.0 \pm 7.6$ & $1.6 \pm 4.5$ & $1.7 \pm 6.8$ & $2.6 \pm 7.5$ & $2.1 \pm 10.6$ \\
\hline Respiratory support required (\%) & $623(30.3)$ & $196(26.0)$ & $106(30.3)$ & $124(33.9)$ & $197(33.7)$ \\
\hline Days on respiratory support (mean $\pm S D$ ) & $2.3 \pm 7.7$ & $1.6 \pm 4.7$ & $2.5 \pm 6.7$ & $2.7 \pm 7.3$ & $2.9 \pm 11.0$ \\
\hline Intubation required (\%) & $198(9.6)$ & $83(11.0)$ & $19(5.4)$ & $41(11.2)$ & $55(9.4)$ \\
\hline Days on intubation (mean $\pm S D$ ) & $0.9 \pm 5.2$ & $0.7 \pm 3.0$ & $0.8 \pm 4.8$ & $1.3 \pm 6.2$ & $1.0 \pm 6.8$ \\
\hline
\end{tabular}

Abbreviations: BPD, bronchopulmonary dysplasia; CLD, chronic lung disease; HSCHD, hemodynamically significant congenital heart disease; PICU, pediatric intensive care unit; SD, standard deviation.

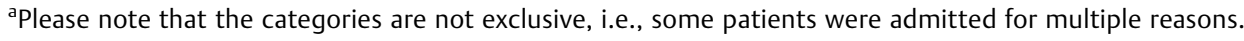

\begin{tabular}{|c|c|c|c|}
\hline Group & HR & $95 \% \mathrm{Cl}$ & $p$-Value \\
\hline Patients with siblings & 1.8 & $1.3-2.5$ & 0.001 \\
\hline Siblings attending daycare & 1.6 & $1.3-2.1$ & $<0.0005$ \\
\hline Familial history of atopy & 1.3 & $1.0-1.7$ & 0.022 \\
\hline $\begin{array}{l}\text { Exposure to smoking } \\
\text { in the household }\end{array}$ & 1.6 & $1.2-2.0$ & $<0.0005$ \\
\hline $\begin{array}{l}\text { Household greater } \\
\text { than } 5 \text { people, }\end{array}$ & 1.7 & $1.3-2.2$ & $<0.0005$ \\
\hline Indication & & & 0.001 \\
\hline $\begin{array}{l}\text { Prematurity } \\
\text { (comparator) }\end{array}$ & - & - & - \\
\hline $\mathrm{BPD} / \mathrm{CLD}$ & 1.9 & $1.3-2.7$ & 0.001 \\
\hline HSCHD & 1.7 & $1.2-2.4$ & 0.005 \\
\hline Miscellaneous & 1.2 & $0.9-1.7$ & 0.237 \\
\hline
\end{tabular}

Abbreviations: BPD, bronchopulmonary dysplasia; CLD, chronic lung disease; HR, hazard ratio; HSCHD, hemodynamically significant congenital heart disease; RSV, respiratory syncytial virus.

were: daycare attendance, siblings, atopy in the family, multiple birth, smoking exposure, and household crowding. These risk factors are similar to those noted in other studies, but given our larger population, there is a higher level of statistical significance. The RSVH risk increased significantly and substantially with increasing number of risk factors.

We confirmed that the commonest indication for PVZ was prematurity (63.3\%). Infants in two other groups, BPD/CLD, (8.4\%) and HSCHD (10.5\%) remained prominent. These three groups feature in national RSV prophylaxis guidelines from pediatric societies, such as the United States, ${ }^{31}$ Canada, ${ }^{6}$ Italy, ${ }^{32}$, and Saudi Arabia. ${ }^{33}$ These three high risk groups were also prominent in the reports from the United States, ${ }^{34}$ Bosnia, and Herzegovina ${ }^{15}$ and from Germany. ${ }^{16}$ However, the report from Bosnia and Herzegovina differed from ours and the German report in that HSCHD (34.1\%) was almost as common an indication as prematurity (49.2\%).

An important new finding is that PVZ was administered to $17.8 \%$ children in whom the indication was classified as "miscellaneous." This group comprised children with Trisomy 21, airway anomalies, pulmonary disorders, cystic fibrosis, neurological impairments, immunodeficiency, and cardiac disease $>2$ years of age. Some had multiple indications for PVZ (4.3\%). It also included children who did not fit neatly into a simple classification. Not only were there more children in the "miscellaneous" group in this report than three other studies, ${ }^{15,16,34}$ we have shown a striking increase over time. In our earlier report, ${ }^{7} 70.8 \%$ received PVZ for prematurity, but in the whole period (2005-2017) this fell to $63.3 \%$. This is likely due to an increase in the "miscellaneous" group from $4.4 \%$ (2005/2006) to $22.5 \%$ (2016/2017) and may be related to an increase in the number of children seen as vulnerable by their physicians, even if they did not have primary indications. ${ }^{23}$ The prominence of the "miscellaneous" group sharply contrasts with reports from Bosnia and Herzegovina ${ }^{15}$ and Germany ${ }^{16}$ where the "miscellaneous" group comprised 2.2 and $5 \%$ of the population, respectively. There is no clear evidence to explain this difference, but we speculate the differences may relate to 
Table 7 Demographic differences between RSV-positive hospitalized children and RSV-negative hospitalized children

\begin{tabular}{|c|c|c|c|c|}
\hline & $\begin{array}{l}\text { RSV-positive } \\
\text { hospitalized } \\
\text { children } n=334\end{array}$ & $\begin{array}{l}\text { RSV-negative } \\
\text { hospitalized/ } \\
\text { Non-hospitalized } \\
\text { children } n=24,669\end{array}$ & $x^{2}$ or $F(\mathrm{~d} f)$ & p-Value \\
\hline Male (\%) & $171(51.2)$ & $13,912(56.5)$ & $3.7(1)$ & 0.054 \\
\hline Caucasian (\%) & $230(68.9)$ & $16,933(68.6)$ & $0.01(1)$ & 0.931 \\
\hline Daycare attendance (\%) & $29(8.7)$ & $938(3.8)$ & $21.0(1)$ & $<0.0005$ \\
\hline Atopy in family (\%) & $165(49.4)$ & $9,869(40.0)$ & $12.2(1)$ & $<0.0005$ \\
\hline Multiple birth (\%) & $84(25.1)$ & $6,865(27.8)$ & $1.2(1)$ & 0.278 \\
\hline Smoking in home (\%) & $114(34.1)$ & $6,485(26.3)$ & $10.4(1)$ & 0.001 \\
\hline With siblings (\%) & $261(78.1)$ & $15,718(63.7)$ & $29.7(1)$ & $<0.0005$ \\
\hline With siblings in daycare (\%) & $105(31.4)$ & $4,598(18.6)$ & $35.3(1)$ & $<0.0005$ \\
\hline With $\geq 5$ people in household (\%) & $120(35.9)$ & $5,925(24.0)$ & $25.5(1)$ & $<0.0005$ \\
\hline Mean enrollment age (month $\pm S D$ ) & $6.7 \pm 8.0$ & $5.7 \pm 6.4$ & $9.3(1)$ & 0.002 \\
\hline Mean gestational age $(w k \pm S D)$ & $32.5 \pm 5.2$ & $32.6 \pm 5.0$ & $0.3(1)$ & 0.603 \\
\hline Mean birth weight $(g \pm S D)$ & $1,935.8 \pm 1,046.8$ & $1,935.9 \pm 985.2$ & $<0.01(1)$ & 0.998 \\
\hline Mean enrollment weight $(\mathrm{g} \pm \mathrm{SD})$ & $5,410.0 \pm 3,123.3$ & $5,113.8 \pm 2,962.0$ & $3.3(1)$ & 0.070 \\
\hline
\end{tabular}

Abbreviations: RSV, respiratory syncytial virus; SD, standard deviation.

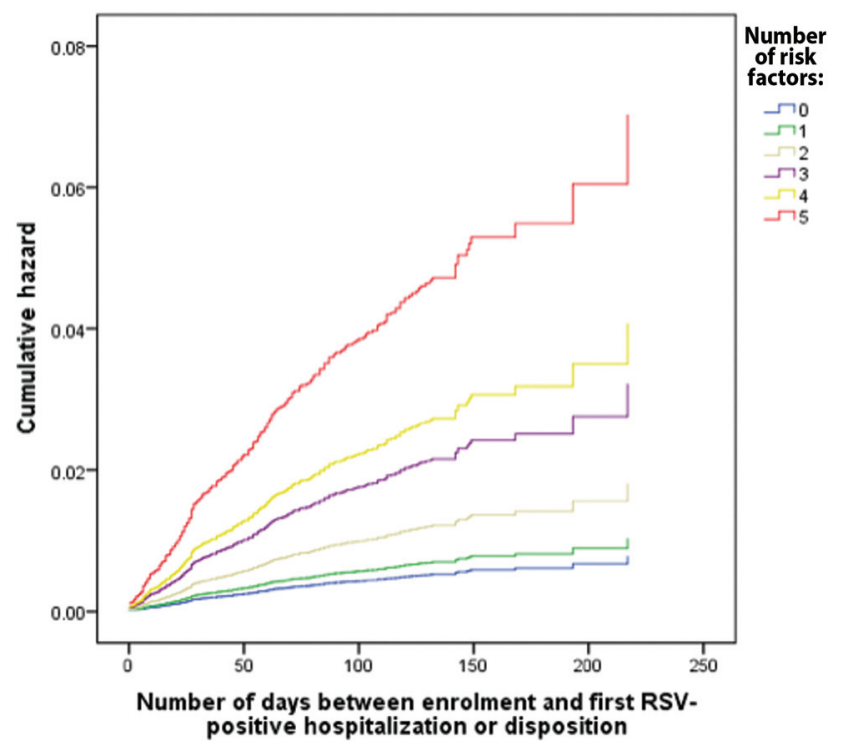

Fig. 3 Hazard curve for Cox's proportional analysis based on the number of risk factors. Risk factors included: attending daycare, siblings, siblings in daycare, smoking exposure, family history of atopy, and household crowding ( $\geq 5$ individuals in the household). RSV, respiratory syncytial virus.

the degree governments are willing to accept physician advice on determining priorities and assessing evidence.

Increased use of PVZ in the "miscellaneous" category is a function of individual clinical decisions. Hints of such activity are noted in other studies. Hampp et $\mathrm{al}^{35}$ found that PVZ was used more "in children with multiple indications," and the authors were concerned that "one-third of the doses were administered outside of guidelines." We hypothesize that the increased PVZ use is related to the known severity of RSV disease in various vulnerable subpopulations and the desire to avoid additional morbidities. In addition,

\begin{tabular}{|c|c|c|c|}
\hline Group & HR & $95 \% \mathrm{Cl}$ & $p$-Value \\
\hline Patients with siblings & 1.8 & 1.3-2.5, & 0.001 \\
\hline Siblings attending daycare & 1.5 & 1.1-2.0, & 0.005 \\
\hline Familial history of atopy & 1.3 & $1.0-1.7$ & 0.022 \\
\hline $\begin{array}{l}\text { Exposure to smoking } \\
\text { in the household }\end{array}$ & 1.5 & $1.2-2.0$ & 0.001 \\
\hline Household $>5$ people, & 1.7 & $1.3-2.2$ & $<0.0005$ \\
\hline
\end{tabular}

Abbreviations: $\mathrm{Cl}$, confidence interval; $\mathrm{HR}$, hazard ratio; RSV, respiratory syncytial virus.

the number of children regarded as "medically complex" is increasing in all jurisdictions, implying that more children are at risk of RSV disease. Two reports indicate that children admitted to the PICU because of RSV disease had at least one pre-existing medical disorder, and $54 \%$ had more than two conditions. These included neuromuscular disease, airway anomalies, chromosomal aberrations, cardiac lesions, CLD/BPD, immunodeficiency, and prematurity. ${ }^{36,37}$

The Canadian Pediatric Society 6 and American Academy of Pediatrics ${ }^{27}$ discourage PVZ use in children with underlying medical disorders unless pulmonary status is already compromised. Nevertheless, children with a range of complexities, for example Trisomy 21 and neuromuscular impairment, are still noted to be at high risk of admission with RSV infection. ${ }^{36,37}$ Our data show a discrepancy between physician practice and consensus statements. We speculate that physicians act as advocates for children, while authors of a consensus statement, justifiably, focus almost solely on the strength of evidence. ${ }^{14,38}$ The sample size required in the pivotal studies on prematurity and HSCHD, were respectively 1,502 and $1,287.4,5$ Given the limitations of conducting largescale studies, we assert that RSVH outcomes provide useful 


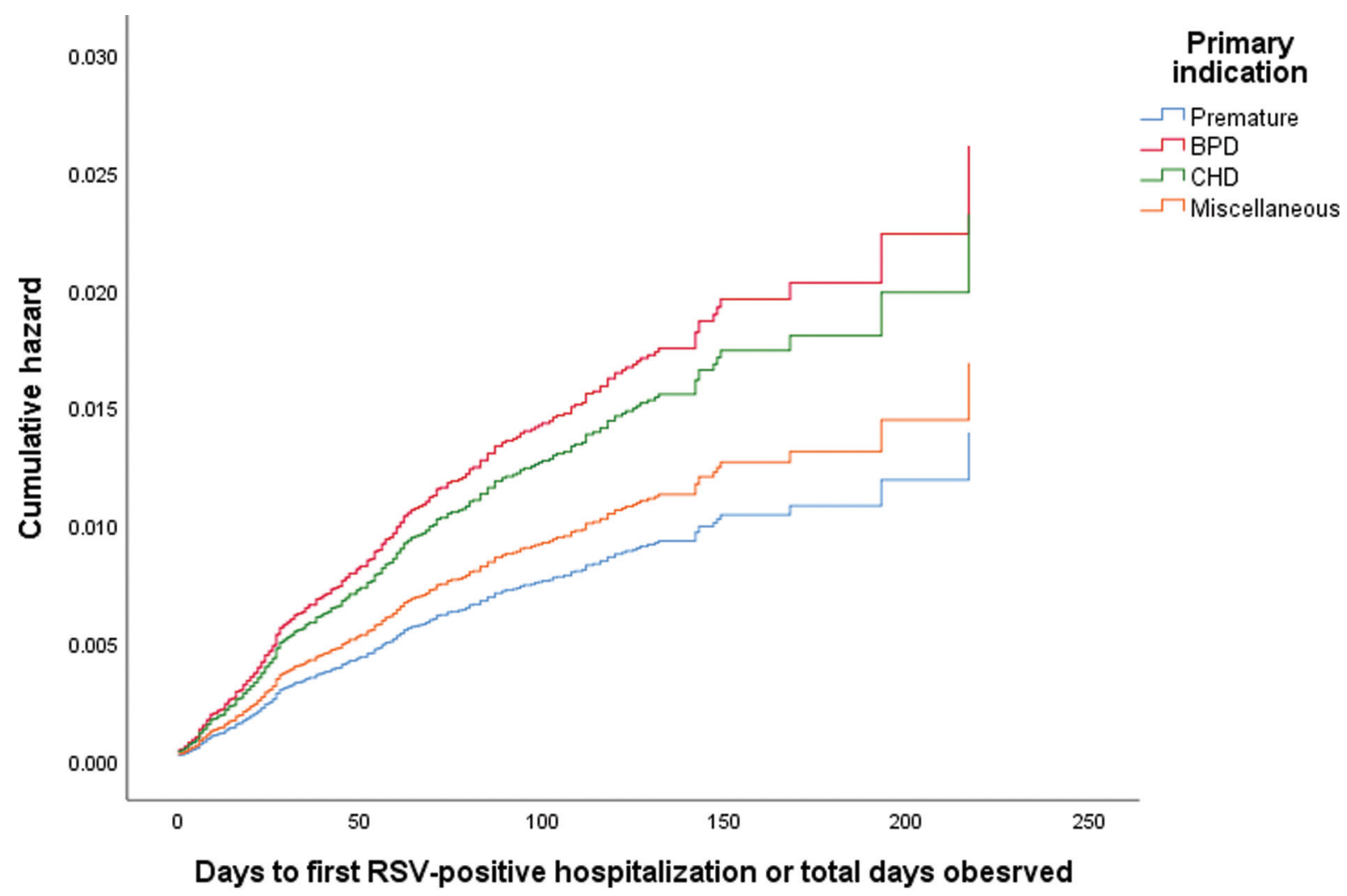

Fig. 4 Hazard curve for Cox's proportional analysis for respiratory syncytial virus hospitalization based on indication. BPD, bronchopulmonary dysplasia; CHD, congenital heart disease; RSV, respiratory syncytial virus.

information for clinicians and decision-makers. The evidence, though not as persuasive as an RCT, is more powerful than an underpowered study in a small population. Moreover, it is unlikely that clinicians would countenance use of a placebo in such vulnerable children.

One of the objectives of this study was to examine safety. We identified three SAEs, none of them fatal. Our data confirm that adverse events are rare and minor, as did the report by Simon et al. ${ }^{16}$ The latter study described 668 SAEs with 63,572 PVZ injections, with the vast majority being respiratory infections. Eight SAEs may have had a possible or probable relation to PVZ, none with persistent impairment or disability. Our data adds to the evidence that PVZ appears safe in children with a variety of complex conditions.

Several limitations are common to registries of treatment. First is the inability to compare infants in our study with highrisk infants who did not receive PVZ. This limitation is unavoidable, as most high-risk infants in Canada currently receive prophylaxis. Second, selection bias may have occurred through individual agreement to participate in the study. Third, the true incidence of RSVH is likely underestimated since all patients were not tested for RSV and a range of diagnostic tests were employed to detect RSV across the seasons.

\section{Conclusion}

We studied that 25,003 children from diverse populations across Canada received PVZ and gathered data relevant for clinicians and decision-makers in other developed countries.
We confirmed the relative safety of PVZ in the absence of an RCT, and the medical and social risk factors for RSVH. This study highlights the increasing use of PVZ in children with complex disorders, which we attribute to thoughtful physicians acting in the best interests of already vulnerable infants. While the best evidence for PVZ use would be an RCT, given the logistic difficulties, the information we have provided on RSVH is acceptable supportive evidence. A vaccine that protects against RSV is urgently required, but passive immunization with a monoclonal antibody may still have a preventive role especially in extremely preterm infants.

Registration

ClinicalTrials.gov Identifier: NCT00420966.

Funding

The Canadian Respiratory Syncytial Virus Evaluation Study of Palivizumab (CARESS) is funded by an investigator-initiated grant from AbbVie Corporation (A05-130).

\section{Conflict of Interest}

B.A.P., I.M., K.L.L., and C.L.B. have received investigatorinitiated research funding or received compensation as advisors or lecturers from AbbVie Corporation, Merck and MedImmune. A.L. has no conflicts of interest to disclose. I. M. reports grant from AbbVie CANADA, other from AbbVie Canada, during the conduct of the study; grants from Regeneron, grants from Medimmune, outside the submitted work. C.L.B. reports grant from Abbvie, during the 
conduct of the study; other from Regeneron, outside the submitted work. B.A.P. reports grants and personal fees from AbbVie Incorporated, personal fees from Merck, during the conduct of the study. K.L.L. reports grants and personal fees from AbbVie, outside the submitted work. A.L. reports grant from AbbVie Canada, during the conduct of the study.

\section{Acknowledgments}

The authors would like to thank the following investigators in the CARESS 2005-2017 seasons: Dr. Candice Bjornson, MD, FRCPC and Dr. Ian Mitchell, MD, FRCPC (Alberta Children's Hospital), Dr. Mark Chilvers, MD, BSc, MRCPCH (BC Children's Hospital), Dr. Georges Caouette, MD, MSc, FRCPC (Centre Hospitalier de l'Université [CHU] Laval), Dr. Marc Lebel, MD, FRCPC (CHU Sainte-Justine), Dr. Mario Eddy Dumas, MD, MSc (CHU Sherbrooke), Dr. Charles Hui, MD, FRCPC (Children's Hospital of Eastern Ontario), Dr. Ann Bayliss, MD, FRCPC (Credit Valley Hospital), Dr. Bruno DiGravio, MD, FRCPC (Grand River Hospital), Dr. Jean-Pierre Doray, MD (Hôpital Charles LeMoyne), Dr. Dora Stinson, MD, FRCPC, FAAP (IWK Health Centre), Dr. Apostolos Papageorgiou, MD, FRCPC, FAAP (Jewish General Hospital), Dr. Marianna Mitchell, MD, FRCPC (Lakeridge Health Oshawa), Dr. David Lee, MB BS, FRCPC, and Dr. April Price, MD, FRCPC, FCCP (London Health Sciences Centre), Dr. Aaron Chiu, MD, FRCPC, FCCP (Manitoba Institute of Child Health), Dr. Bosco Paes, MD, FRCPC (McMaster Children's Hospital), Dr. Roderick Canning, MB, FRCPC (Moncton Hospital), Dr. Anne-Marie Canakis, MDCM, FRCPC and Dr. Jesse Papenburg, MD, FRCPC (Montreal Children's Hospital), Dr. Karel O'Brien, MD, FRCPC (Mount Sinai Hospital), Dr. Karen Chang, MBBS, FRCPC (Rouge Valley Hospital), Dr. Koravangattu Sankaran, MB BS, FRCPC (Royal University Hospital), Dr. Vincent Ho, MD, FRCPC (Royal Victoria Hospital), Dr. Larry Chang, MD (Southlake Regional Health Centre), Dr. Cecil Ojah, MBBS, FRCPC (St. John Regional Hospital), Dr. Sanja Avdic, MD (St Joseph's Health Centre), Dr. Upton Allen, MBBS, MSc, FAAP, FRCPC (Sick Kids Hospital), Dr. Carina Majaesic, MD, PhD, FRCPC (Stollery Children's Hospital), Dr. Marc Blayney, MB BCh, FRCPI, FRCPC (Sudbury Regional Hospital), Dr. Brian Simmons, BM FRCPC, FAAP (Sunnybrook Health Sciences Centre), Mr. Kiang Tang, BScPhm and Dr. Jelena Popovic, MD (Toronto East General Hospital), Dr. Frank Jagdis, MD (Victoria General Hospital), Dr. Ivor Margolis, MD (William Osler Health Centre) and Dr. Godfrey Bacheyie, MD, FAAP (Windsor Regional Hospital).

The authors would also like to thank all the nurses, coordinators, and families for their dedication and participation in this project.

\section{References}

1 Borchers AT, Chang C, Gershwin ME, Gershwin LJ. Respiratory syncytial virus-a comprehensive review. Clin Rev Allergy Immunol 2013;45(03):331-379
2 Higgins D, Trujillo C, Keech C. Advances in RSV vaccine research and development-a global agenda. Vaccine 2016;34(26):2870-2875

3 Resch B. Product review on the monoclonal antibody palivizumab for prevention of respiratory syncytial virus infection. Hum Vaccin Immunother 2017;13(09):2138-2149

4 Palivizumab, a humanized respiratory syncytial virus monoclonal antibody, reduces hospitalization from respiratory syncytial virus infection in high-risk infants. The IMpact-RSV Study Group. Pediatrics 1998;102(3, pt. 1):531-537

5 Feltes TF, Cabalka AK, Meissner HC, et al; Cardiac Synagis Study Group. Palivizumab prophylaxis reduces hospitalization due to respiratory syncytial virus in young children with hemodynamically significant congenital heart disease. J Pediatr 2003;143(04): 532-540

6 Robinson JL, Le Saux NCanadian Paediatric Society, Infectious Diseases and Immunization Committee. Preventing hospitalizations for respiratory syncytial virus infection. Paediatr Child Health 2015;20(06):321-333

7 Mitchell I, Paes BA, Li A, Lanctôt KLCARESS investigators. CARESS: the Canadian registry of palivizumab. Pediatr Infect Dis J 2011;30 (08):651-655

8 Paes B, Mitchell I, Li A, Harimoto T, Lanctôt KL. Respiratory-related hospitalizations following prophylaxis in the Canadian registry for palivizumab (2005-2012) compared to other international registries. Clin Dev Immunol 2013;2013:917068

9 Homaira N, Rawlinson W, Snelling TL, Jaffe A. Effectiveness of palivizumab in preventing RSV hospitalization in high risk children: a real-world perspective. Int J Pediatr 2014;2014:571609

10 Moore HC, de Klerk N, Richmond PC, et al. Effectiveness of palivizumab against respiratory syncytial virus: cohort and case series analysis. J Pediatr 2019;214:121-127.e1

11 Simon A, Gehrmann S, Wagenpfeil G, Wagenpfeil S. Palivizumab use in infants with Down syndrome-report from the German Synagis $^{\mathrm{TM}}$ Registry 2009-2016. Eur J Pediatr 2018;177(06): 903-911

12 Kool-Houweling LM, Penning-van Beest FJ, Bezemer ID, van Lingen RA, Herings RM. Infants born before 32 weeks of gestation or with respiratory disease are most likely to receive palivizumab in the Netherlands. Acta Paediatr 2015;104(09):927-932

13 Haerskjold A, Henriksen L, Way S, et al. The Danish National Prescription Registry in studies of a biological pharmaceutical: palivizumab-validation against two external data sources. Clin Epidemiol 2015;7:305-312

14 Wang DY, Saleem M, Paes BA, Mitchell I, Li A, Lanctôt KLCARESS Investigators. Respiratory syncytial virus prophylaxis in neurologic and muscular disorders in the Canadian respiratory syncytial virus evaluation study of palivizumab. Pediatr Infect Dis J 2019;38(08):775-780

15 Heljic S, Maksic H, Begic H, et al. Palivizumab prophylaxis of RSV infections in Bosnia and Herzegovina. J Pediatr Neonat Individual Med. 2016;5:e050129

16 Simon A, Gehrmann S, Wagenpfeil G, Wagenpfeil S. Use of palivizumab in Germany-report from the German Synagis ${ }^{\mathrm{TM}}$ Registry 2009-2016. Klin Padiatr 2018;230(05):263-269

17 Paes B, Mitchell I, Li A, Lanctôt KL. Respiratory hospitalizations and respiratory syncytial virus prophylaxis in special populations. Eur J Pediatr 2012;171(05):833-841

18 Luna MS, Manzoni P, Paes B, et al. Expert consensus on palivizumab use for respiratory syncytial virus in developed countries. Paediatr Respir Rev 2020;33:35-44

19 Manzoni P, Paes B, Lanctôt KL, et al. Outcomes of infants receiving palivizumab prophylaxis for respiratory syncytial virus in Canada and Italy. Pediatr Infect Dis J 2017;36(01):2-8

20 Kashiwagi T, Okada Y, Nomoto K. Palivizumab prophylaxis against respiratory syncytial virus infection in children with immunocompromised conditions or down syndrome: a multicenter, post-marketing surveillance in Japan. Paediatr Drugs 2018;20(01):97-104 
21 Berger TM, Fontana M, Stocker M. The journey towards lung protective respiratory support in preterm neonates. Neonatology 2013;104(04):265-274

22 Gonska T, Ratjen F. Newborn screening for cystic fibrosis. Expert Rev Respir Med 2015;9(05):619-631

23 Berry JG, Hall M, Cohen E, O'Neill M, Feudtner C. Ways to identify children with medical complexity and the importance of why. J Pediatr 2015;167(02):229-237

24 Law BJ, Langley JM, Allen U, et al. The Pediatric Investigators Collaborative Network on Infections in Canada study of predictors of hospitalization for respiratory syncytial virus infection for infants born at 33 through 35 completed weeks of gestation. Pediatr Infect Dis J 2004;23(09):806-814

25 Paes BA, Craig C, Pigott W, Latchman A. Seasonal respiratory syncytial virus prophylaxis based on predetermined dates versus regional surveillance data. Pediatr Infect Dis J 2013;32(09):e360-e364

26 SPSS Inc. Released 2008. SPSS Statistics for Windows, Version 17.0 Chicago: SPSS Inc. USA; 2008

27 Baranov AA, Ivanov DO, Aliamovskaia GA, et al. Palivizumab: four seasons in Russia. Vestn Ross Akad Med Nauk 2014;(7-8):54-66, 68

28 Borecka R, Lauterbach R. Compliance with the RSV immunoprophylaxis dosing schedule in the Polish registry for palivizumab (2008-2014). Dev Period Med 2018;22(04):308-314

29 Lacaze-Masmonteil T, Rozé JC, Fauroux BFrench Pediatricians' Group of Sunagis Patients' Name-Based Programs. Incidence of respiratory syncytial virus-related hospitalizations in high-risk children: followup of a national cohort of infants treated with Palivizumab as RSV prophylaxis. Pediatr Pulmonol 2002;34(03):181-188

30 Bennett MV, McLaurin K, Ambrose C, Lee HC. Population-based trends and underlying risk factors for infant respiratory syncytial virus and bronchiolitis hospitalizations. PLoS One 2018;13(10): e0205399

31 American Academy of Pediatrics Committee on Infectious Diseases American Academy of Pediatrics Bronchiolitis Guidelines Committee. Updated guidance for palivizumab prophylaxis among infants and young children at increased risk of hospitalization for respiratory syncytial virus infection. Pediatrics 2014; 134(02):e620-e638

32 Bollani L, Baraldi E, Chirico G, et al; Italian Society of Neonatology. Revised recommendations concerning palivizumab prophylaxis for respiratory syncytial virus (RSV). Ital J Pediatr 2015;41:97

33 Al Aql F, Al-Hajjar S, Bin Mahmoud L, et al. Int J Pediatr. Adolesc Med 2016;3:38-42

34 Frogel M, Nerwen C, Cohen A, VanVeldhuisen P, Harrington M, Boron MPalivizumab Outcomes Registry Group. Prevention of hospitalization due to respiratory syncytial virus: results from the Palivizumab Outcomes Registry. J Perinatol 2008;28(07): 511-517

35 Hampp C, Saidi AS, Winterstein AG. Palivizumab utilization and compliance: trends in respiratory syncytial virus prophylaxis in Florida. J Pediatr 2010;156(06):953-959.e1

36 Thorburn K. Pre-existing disease is associated with a significantly higher risk of death in severe respiratory syncytial virus infection. Arch Dis Child 2009;94(02):99-103

37 Kang JM, Lee J, Kim YK, et al. Pediatric intensive care unit admission due to respiratory syncytial virus: retrospective multicenter study. Pediatr Int (Roma) 2019;61(07):688-696

38 Paes B, Mitra S. Palivizumab for children with Down syndrome: is the time right for a universal recommendation? Arch Dis Child 2019;104(08):719-721 